S.rancista Dlena extion ex? reend 185y.

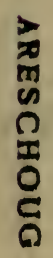

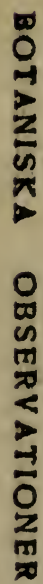

0
$\vdots$
$\vdots$
$\vdots$
$\vdots$ 


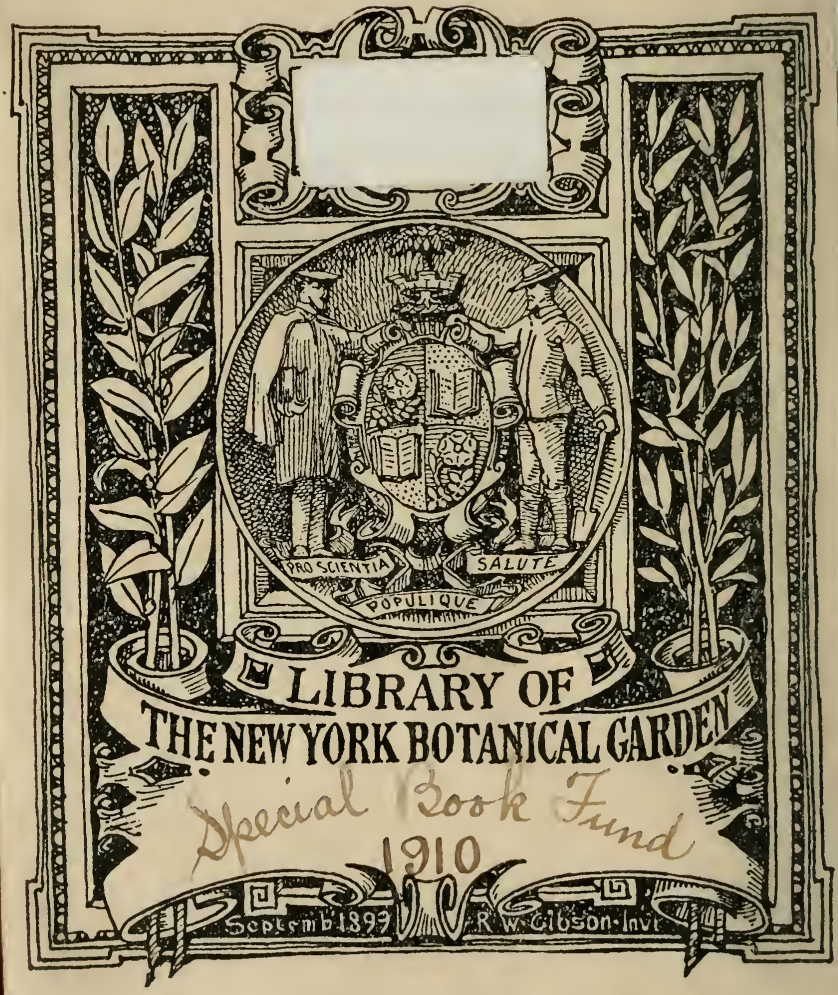





\title{
Botaniska Observationer.
}

\author{
Akademisk afhandling,
}

som

med Vidberönda Filosoliska Fakultetens tillstånd

kommer att offentligen försvaras

af

F. W. C. ARESCHOUG,

Filos. Mag.

Pá Carolinska Akademien den 19 April 1854.

p. v. $t$.

\section{L und,}

tryckt uti Berlingska Boktrycleriet,

1854. 

De observationer, som komma att utgöra föremâlet för nārvarande afbandling, hafva hufvudsakligen afseende pâ nåģra nıera svârbestāmda slāgten, lıvilka jağ en längre tid eggnat en synnerlig uppmärksamhet. Skânes Flora har redan lānge genom många utmärkta Botanisters förenade bemödanden varit sâ kānd, att man om den med skāl kan säga, att der för en yngre naturforskare mycket finnes att inhemta, föga att utreda. Sålunda âterstå ānnu blott några få, s. k. kritiska văxter, som troligen ānnu länge skola hâlla forskarnes tankar delade, och vid bvilka jag i denna uppsatts vill bifoga resultaten af mina undersökningar. 


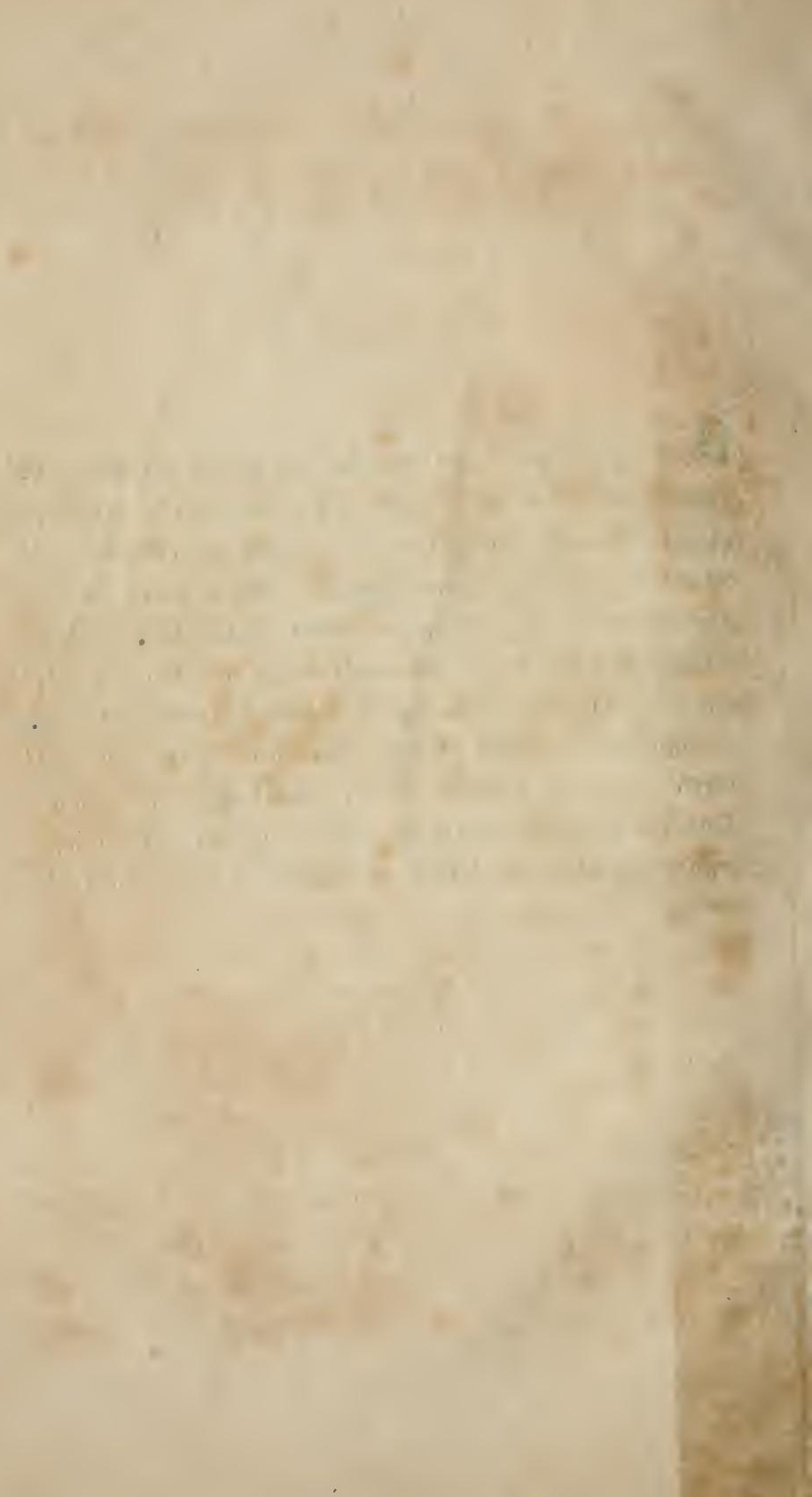




\section{Mentha L.}

D。 arter, som höra till detta slāgte, äro i högre grad, än de flesta andra văxter, sâ văl till habitus som karaliterer underkastade förändringar. Vid knappt nâgot annat slägte är en noggrann kännedom om växtens hela anlag till den grad af nöden. Om man derföre blott fäster sig vid de olikheter, som visa sig mellan särskilta exemplar och förbiser det inflytande, som yttre omständigheter kunnat utöfra, så skall man erhâlla och har āfren genom eft dỵlikt förfarande erhâllit en mängd s. k. arter, som vid första pâseende sỵnas rătt văl begränsade. Ocksâ kan văl knappast nâgot annat slāgte jemföras med detta i anseende till măngden af arter utan ringaste artrăttighet. Mânga författare hafıa till grund lör arthegränsningen lağt hârigheten, Jlomkransarnes olika förhâllande, stândarsträngarnes längd $\mathrm{m}$. m., hrilket allt blott förorsakas af lokalens olika beskaffenbet. På skưgrrika fultigga ställen blir nemligen växten mera glatt, bladen starkare utvecklade på blommornas bekostnad, hrarigenom de blifva lângt skaftade och nâ betydligt öfver blomkiransarne, som blifva fâ och glesblommiga samt försvinna slutligen alldeles $\mathrm{i}$ de öfre bladrecken. De arter, som höra till Mentha petiolata, äro isynnerhet 
föränderliga och af särskilta författare högst olika beskrifna. I Sverige finnas af denna grupp fyra som egna arter upptagna formcr, nemligen $M$. aquatica, sativa, gentilis och arvensis, vid luvilka jag här vill bifoga några anmärkningar.

M. aquatica (L. fl. suec. pag. 202) verticillis in capitula congestis vel remotis, calycibus apice primo glabrescentibus, tubulosis dentatis, dentibus triangulari-subulatis, multo longioribus quam latioribus.

Denna art anse de flesta författare isy̧nnerhet utmärkas af de i hufvud samlade blomkransarne. Af skäl, som nedanföre skola anföras, tillägga vi $M$. aquatica en forma verticillata. Den stora mängd af rarieteter, som höra till denna art, kunna lämpligast efter Fr. Nov. Ed. alt. hänföras under följande trenne hufvudformer:

A) Capitata, verticillis in capitula congestis, staminibus sæpe longe exsertis, foliis omnibus petiolatis.

Denna form tyckes efter beskirifningen i Fl. Suec. Ed. alt. och Sp. pl. vara den älta Linnéanska M. aquatica. Den vexer talrikt på öppna och fuktiga ställen.

B) Subspicata, verticillis approximatis sessilibus, foliis floralibus sursum decrescentibus, verticillos non longe superantibus, sessilibus bracteiformibus, staminibus vulgo inclusis.

Ilit bör M. aquatica B. verticillata $\beta$ caudata Wimm. §̧ Grab. Fl. Siles. pağ 180 hänföras.

Liksom föregående afdelning, variera äfven hithörande former betydligt med afseende på hârigheten. Genom talrika öfvergângar förbindes denna med föregående och efterföljande afdelning. Stundom bilda blomkransarne öfversta spetsen af stjelken, stundom sitta ett par blad 
ofvanom den öfversta blomkransen, hvilka dock vanligen äro mycket små och fürkrympta. Den-visar en ganska stor analogi med hufvudformen af M. gentilis.

C) Verticillata, verticillis omnibus remotis pedunculatis, foliis omnibus magnitudine subæqualibus, petiolatis, verticillos longe superantibus, caule apice comoso, staminibus plerumque inclusis.

M. aquatica B. verticillata $\beta$ æqualifolia Wim. $\&$ Grab. FI. Siles. p. 180 ; M. aquatica var. sativa Sm. FL. Brit. p. 617; M. sativa Fr. Nor. Ed. prim. pag. 70; M. aquatica \& subsativa Fr. Nov. Ed. alt. pag. 183.

Hit hörande former pläga vanligen lıänföras till $M$. sativa eller arvensis. Man har nemligen ansett Menthce caule determinato ocb Menthce caule indeterminato skarpt söndrade frân hvarandra och på denna grund hänfört $M$. aquatica verticillata till någon af dessa begge arter. Jag för min del tror dock ej, att sâ stor vigt bör lăggas på detta förbâllande. $M$. aquatica subspicata, hvilken văl ingen vill förneka vara en varietet af $\boldsymbol{M}$. aquatica, bildar nemligen en förenande lānk mellan dessa hegge extremer. Redan der visa sig nâgra blad i toppen, hrilka dock liksom alla de öfriga bladen, som stödja blomkransarne, äro smâ och förkrympta. Ven på skuggrika och fuktiga ställen, hvarest $M$. aquatica verticillata fürekommer, blifva bladen, såsom ofta laănder pâ dylika lokaler, starlit utvecklade på bekostnad af blomkransarne; dessa sednare blifva sliaftade, fâ och glesblommiga, samt försvinna alldeles i de öfrersta bladvecken; bladen nå betydligt öfver blomkransarne och hela vexten blir mera spenslig. På dessa grunder anser jag denna afart böra hänföras till $M$. aquatica och ingalunda, såsom 
Bentham (i De Cand. Prodr. Regn. Veg. tom. XII) till $M$. arvensis, frân hvilken den afviker genom blomfodrets form och de smala sylspetsade blomfodertänderna, genom hvilka kännetecken jag anser $M$. aquatica och arvensis bäst kunna âtskiljas.

M. sativa Fr. Herb. Norm. (Fasc. 2, n:o 26) kan på intet sătt sliiljas frân denna afart. I allmänhet synes $M$. sativa blott bestå af formæ verticillatæ af $M$. gentilis och aquatica. Vi ega nemligen en form af $M$. gentilis, som förekommer i Småland, Bohuslän m. fl. st., hvilken stâr i ungefärligen samma förhâllande till hufvudformen, som $M$. aquatica verticillata till $M$. aqu. subspicala. $M$. sativa Fr. (Nov. Ed. alt. pag. 184) synes höra till denna form, emedan blomfodrets hârighet fullkomligt öfverensstämmer med förhâllandet hos $M$. gentilis och emedan densamma, liksom M. gentilis, säges blott vara förvildad i Sverige, dă deremot $M$. sativa Herb. Norm. och Mant. tert. förekommer fullkomliggt vild pâ fuktiga och skuggrika ställen i Skâne t. ex. vid Esperöıl. M. aquatica $\varepsilon$ subsativa Fr. Nov. Ed. alt. tyckes sedan blifvit kallad sativa $L$., då deremot M. sativa Fr. Nov. Ed. alt. sedermera i Summ. Veg. blifvit förd till M. gentilis under namn af Agardhiana. M. gentilis L. (Sp. pl. 2 pag. 805 ) verticillis remotis densis, cano-strigosis, calyce tubuloso-campanulato, hasi primo glabrescente, dentibus triangulari-lanceolatis, longioribus quam latioribus.

Genom sina vanligen små tätt samlade, grâludna och tätblommiga blomkransar, sitt blomfoder, som här först börjar blifva glatt vid basen, då förhâllandet hos M. aquatica är ett motsatt, samt genom sin egendomliga lukt och olika växt- 
stälen skiljes den frâll $M$, aquatica. I Sverige förekommer den nemligen blott förvildad. Ilárigheten, bladoch blomskaftens längd, blommornas storlek samt stândarnes längd lemma ej nägı́a constanta kảnnetecken.

Med afseende pâ bladskaftens längd hafva vi trenne formförãndringar. Den ena har de öfre bladen, som stödja blomkransarne, mycket smâ, obetydligt längre ăn blombransarne och oskaftade, samt mindre utrecklad bladtofs. Blomkransarne hos denna form äro ãfien af ett större antal och mera närmade intill hvarandra, oskaftade, tätblommiga och mera grâludna. Denna förekommer förvildad pä flera ställen liring Lund och är den ursprungliga M. gentilis. Den står mycket nära $M$. rubra Huds. och förenas med denna af Kock i Syn. Fl. Germ. Ed. Il tom. II, pag. 63̋̈. Derı andra afarten har blomkransarne fâ, glesblommiga och skaftade, samt mera aflägsnade frân bvarandra; bladen, som stödja blomkransarne, äro starkt utvecklade, skaftade och nảende lângt öfver blomkransarne; stjelken är försedd med en fullkomligt utrecklad bladtofs. Exemplar af denna form har jag sett frân Smâland, Bohuslän m. fl. st. Genom M. Agardhiana förenas den med M. gentilis. De äro begge fullkomligt analoga med formce subspicatce och verticillatce af M. aquatica. Den sist beslirifna formen af $M$. gentilis är ofta svâr att skilja frân 11. aquatica verticillata caule comoso; till habitus, lukt och vãxtort sliilja de sigg frân hvarandra, ãfrensom genom blomfodrets hârighet. $M$. aquat. vert. är äfren till färgen mera ljusgrön, dâ $\boldsymbol{M}$. gentitis deremot vanligen ăr mörkgrön. Tillsammans synas de hafva bildat de flesta författares $M$. sativa. 
M. arvensis L. (Fl. suec: pag. 201) verticillis densis remotis, caule semper perfecte comoso, calyce campanulato, dentibus triangulari-ovatis æque latis ac longis.

Genom sitt klocklika blomfoder, breda fodertänder, altid skaftade blad och fullt utvecklade bladtofs skiljes denna utan synnerlig svârighet frân alla de föregâende arterna. Med afseende pâ hårigheten ega vi otaliga varieteter. På fuktiga ställen förekommer i östra Skâne en form, som isynnerhet förtjenar uppmärksamhet. Den har nemligen alldeles glatta hartspunkterade, utmårkt klocklika blomfoder, med ovanligt breda fodertänder; blomkransarne äro smâ klotformiğa, oskaftade med tätt sammanpackade blommor. Bladen äro små ovala, sågade och nästan glatta.

\section{Verbascum Phlomoides L. (Sp. pl. tom. 1 pag. 2033)} caule subtereti, foliis superioribus breviter decurrentibus, infimis petiolatis, omnibus crenatis, utrinque albo-tomentosis, floribus fasciculatis, filamentis duobus glabrescentibus, antheris instructis longioribus quam ceteris.

Denna art, som förut endast nâgra gânger varit sedd i Blekings hafstrakter, förekommer, ehuru sâsom det synes sporadiskt, på âtskilliga ställen i Skâne t. ex. vid Malmö, Ousbyholm.

Bland de Svenska arterna har $V$. Phlomoides den största affinitet med $V$. thapsiforme, från hvilken art den afviker genom sin, till följe af de föga nedlöpande bladen nästan trinda, stjelk, glesare ax och större blommor.

Plantago major $\beta$ uliginosa Wimm. foliis grosse 
dentatis, subcarnosis, pedunculis radicalibus arcuato-decumbentibus.

Pl. major $\beta$ uliginosa Wimm. $\&$ Grab. Fl. Sil. p. 228.

På Skânes och Ölands sandiga och fuktiga hafsstränder har jag funnit denna varietet $\mathrm{i}$ măngd.

\section{Sagina.}

De arter, sum höra till delta slägte, hafva af Prof. Fries i Nov. Ed. alt. blifvit pâ ett utmärkt sātt utredda och bcskrifna. Det mâ vara mig tillâtet att här tillägga en förut ej anmärkt form, som synes stâ pâ gränsen mellan S. apetala och ciliata, till karakterer mest öfverensstämmande med den förra, till habitus och vestsătt med den sednare. Det sỵnes mig ej ảnnu fullkomliggt afgjordt, till bvilken af dessa arter den rättast bör hänföras. Men då den till karakterer ş̣nes mest likna $S$. apetala, tror jag att den tillsvidare bör stâllas sâsom en afart under denna.

S. apetala * ccespitosa caulibus crespitosis erectis cum pedunculis glanduloso-pilosis, foliis subulatis, aristatis, basi parce ciliatis, sepalis duobus exterioribus apice incurvatis, interioribus rectis, omnibus obtusis, capsula semper erecta brevioribus.

Växer pâ sandiga betesmarker i östra Stâne söder oin Stenshufrud.

Frân den egentliga $S$. apetala afviker den genom tufvad, grö̈re och lāgre vest, samt längre blad i förhâllande till internodierna. Från S. ciliata skiljes den genom fullkomligt upprätta gुrenar och frukter, samt trubbiga sepala, men öfrerensstämmer för öfrigt med afseende på vextsăttet. 
Anm. Våra Sagince kunna ganska naturenligt indelas i tvenne grupper, nemligen $S$. procumbens och stricta utgörande den ena, samt S. ciliata och apetala den andra afdelningen. Arterna i den förra afdelningen igenkännas lätt pâ sin ljusgröna färg och glatta växt, i den sednare genom mörkgrön färg och mer eller mindre hårig vāxt. En viss analogi råder äfven mellan arterna $\mathbf{i}$ dessa båda afdelningar, nemligen mellan $S$. procumbens och ciliata, samt S. stricta och apetala. De förra öfverensstämma med afseende på de mer eller mindre nedliggande grenarne och den slutligen lutande capseln, samt de sednare genom upprătta grenar och frukter.

Epilobium hirsutum $L$. Af denna art förekomma tvenne formförändringar, som förtjena anmärkas. Den ena har mera grenig och spenslig stjelk samt eggrundtlancettlika blad, som afsmalna mot begge ändarne. Den andra har mera upprätt, grof och fâgrenig stjelk samt lancettlika blad, som äro mot basen bredast. Den förra förekommer vid skogsbäckar i östra Skâne t. ex. vid Esperöd; den sednare har jag funnit vid gropar och åar $\mathbf{i}$ vestra Skâne.

Cratoggus monogyna var. microphylla foliis minoribus pinnatifidis, utrinque subtomentosis.

Pả torra backar kring Stenshufvud har jag funnit denna varietet.

\section{Rubus I.}

Få slägten erbjuda vid artbeskrifningen så stora svârigheter, som detta. Den otaliga măngd af formförän- 
dringar, som ständigt möta oss vid studium af detta slägte, şnes nära nog guăcka hvarje bemödande att bringa dem under bestämda och begränsade hufvudarter. Till en fullständig kännedom om arternas begränsning är nemligen nödigt, att de noggrannt undersökas i de mest olika och frân hvarandra skilda trakter; emelan det ofta händer, att tvenne sâ kallade arter $i$ en trakt synas rătt vāl bestämda, som i en annan genom mellanliggande former sâ sammanlänkas, att nâgon gräns dem emellan alldeles saknas. Exempel pâ sâdana öfvergângar hafva vi i mảngud både $\mathrm{i}$ djur- och växtriket. Ċtan att derföre vilja utgifva de här nedan gifna artbeskrifningarne för allmānt giltiga, dâ de hufvudsakligen äro resultater af mina undersökningar öfver detta slāgte i östra Skâne, jemförda med exemplar från âtskilliga andra trakter, sâ hoppas jag likrăl att de i någon mân skola bidraga till en fullstāndigare kānnedom af detta mângformiga slảgte. Mảngen skulle visserligen kunna tro, att dessa växter nu äro sâ undersökta, att ej nâgot skulle âterstå att tillägga, dâ vi öfver dem äga sâdana arbeten som Weihes och Nees von Esenbects samt Arrhenii förträflliga Monografi öfver de Srenska arterna; men ānnu âterstâr och skall alltid âterstâ mycket att utreda och tillãgga vid ett så polymorft slägte.

Vanligen har man till grund för grupperingen af Rubi lagt stammens direction eller form och armatur. I synnerbet har stammens direction af mànga författare blifvit anvảnd till indelningsgrund. Utan att vilja frânkänna densamma dess tillbörliga vigt vid artbeskrifningen, tror jag dock att man gâtt för lângt vid indelningen efter derına grund och att det svårligen $\mathrm{i}$ naturen gifves nâgon bestämd 
grăns mellan caulis erectus vel apice arcuatus, c. dtcurvus procumbens, sarmentosus och c. prostratus flagelliformis. Vi se nemligen ofta, att t. ex. de Rubi, som vanligen hafva $c$. decurvus, få, då de sakna stöd, $c$. prostratus. Pâ samma sătt äro äfven många andra kännetecken, som man lagt till grund för indelningar och arter, ofta underkastade så mânga förändringar, att man blott med varsamhet han begagna dem vid framställningen af arterna. De Rubi, som här komma att omnämnas, sönderfalla $\mathrm{i}$ tre ganska naturliga grupper.

Sect. I. Rubi caule suberecto, foliis caulis foliiferi วँ-natis, foliolis duobus infimis subsessilibus, foliis caulis floriferi 3-natis, foliolis infimis subpetiolatis, omnibus utrinque vulgo viridibus, panicula subsimplici, magis minusve corymbosa, pedunculis parce pilosis, sepalis virescentibus, margine albo-tomentosis, petalis obovatis, longe unguiculatis.

Denna grupp, hvars typ $R$. fruticosus bäst uttrycker, karakteriseras i synnerhet af sina gröna, blott i kanten hvitludna blomfoderblad, sina vanligen på begge sidor grröna blad, samt ofta enkla qqastlika inflorescens. Hit höra följande arter:

R. fruticosus $L$. caule foliifero erecto glabro, apice arcuato, angulato lineolato (haud canaliculato), aculeato glabro, foliolis infimis foliorum caulis floriferi brevissime petiolatis, ramorum floriferorum subsessilibus, omnibus superne glabris, subtus plerumque viridi-pubescentibus, panicula corymbosa, sepalis a fructibus reflexis, fructu atro-nitido, acinis numerosis composito. 
H. fruticosus L. Fl. Suec. Ed. II. pag. 172; Wimm. FI. v. Schles. pag. 131; Arrh. Mon. Rub. pag. 23; Fr. Sum. Veg. pag. 164; Hartm. Skand. Fl. 5 Leppl. pag. 157; Reich. Fl. exc. pag. 600 ; Gren. $\$$ Godr. Fl. de Fr. tom. I. pag. ว̈49.

Denna art, som allmãnt förekommer i Skâne, innefattar två former, som vid hastigare påseende synas skarpt âtskilda, men hvilka blott bero af olika vextställen. Många öfvergångar finnas äfven mellan dem.

a littoralis, caule foliifero magis arcuato, obtusangulo, vix lineolato, aculeis caulis $\&$ foliiferi $\&$ floriferi teretibus, parum compressis, validissimis falcatis, foliis coriaceis, superne nitidissimis, petiolis brevibus duris lignosis, panicula ramosa, subcorymbosa.

Förekommer i synnerhet pâ öppna, klipprika hafsstrănder.

Hit tyckes R. nitidus Whe. $\$$ N. ab. Es. Rub. Germ. pag. 19 tab. IV böra föras.

$\beta$ sylvaticus, caule foliifero magis erecto acutangulo lineolato, aculeis caulis foliiferi et floriferi valde compressis debilibus, rectiusculis, foliis tenuissimis superne opacis, subglabris, petiolis gracilibus tenuioribus, elongatis, panicula simplici corymbosa.

R. plicatus Whe. et N. ab. Es. I. c. pag. 15 tab. I.

I sliuggrika skogar på fultig mark anträffas denna varietet i mängd, särdeles vid Esperöd.

Anm. Dessa begge former visa i flera afseenden en viss analogi med formerna nitida och opaca af Rosa canina. 
R. suberectus Anders. caule foliifero suberecto tereti vel obtusangulo, aculeis paucis rectiusculis munito, glabro vel nigro glanduloso, foliolis superne glabris, subtus viridi-pubescentibus, infimis duobus foliorum caulis foliiferi et floriferi sessilibus, panicula subfastigiata, sepalis a fructu reflexis, fructibus glabris atro-sanguineis, acinis pluribus compositis (sec. Arrh. Mon.).

Mag. Gosselman har meddelat mig exemplar af detta species både från Kullabergo och Ousbỵ.

Anm. Då jag ej haft tillfälle att undersöka denna art $\mathrm{i}$ lefvande tillstånd, är det mig omöjligt att afgöra dess affinitet med närstående arter. Flera författare tyckas förena den med R. fruticosus, bvilken den äfven synes stå närmast.

$R$. affinis Whe. caule foliifero suberecto angulato sulcato, aculeis validis rectiusculis armato, foliis superne glabris nitidissimis, subtus viridibus pubescentibus, foliolis infimis duobus foliorum caulis foliiferi et floriferi conspicue pctiolatis, panicula subsimplici elongata, sepalis fructibus adpressis, fructu atro nitido, acinis paucioribus composito.

R. affinis Whe. et N. ab. Es. I. c. pag. 18 tab. III; Bluff et Fingerbuth Comp. Fl. Germ. tom. I pag. 667; Rchb. l. c. pag. 600 ; Arrh. I. c. pag. 20 ; Fr. I. c. pag. 165; Hartm. Skand. FI. pag. 1̋8; Gren. et Godr. I. c. pag. 530 .

Denna art föreliommer i Östra Skâne på flera ställen. Öfvergângen till följande grupp bildas af denna art, som i flera afseenden öfrerensstämmer med R. thyrsoideus. 
Dock anser jag den stâ närmast $R$. fruticosus och till följe deraf böra hänföras till denna afdelning. Frân $R$. fruticosus skiljes den lätteligen genom fârad stam, mera skaftade smâblad, längre utdragen inflorescens samt vanligen utspärrade blomskaft, hvilka hos R. fruticosus äro uppât rigtade, samt till frukten tryckta sepala. Att den bör hănföras till denna afdelning blir tydligt, da man betänker, att blomfoderbladen äro gröna, blott $\mathrm{i}$ kanten hvitludna, samt bladen pá bâđa sidor gröna. $R$. thyrsoideus har visserligen äfren bladen stundom på båda sidor gröna, men detta blott undantagsvis och till följe af lokalens inflỵtande.

Sect. II Rubi caule arcuato, sæpe pilosu et glanduloso, foliis caulis foliiferi $\ddot{b}$-nato-pedatis, floriferi ternatis, foliolis omnibus petiolatis, subtus nireo-tomentosis, panicula composita thyrsoidea, pedunculis dense et patenter pilosis, sepalis albo-tomentosis fructibus maturis reflexis, petalis oboratis basi attenuatis, longe unguiculatis.

Denna grupp karaliteriseras isynnerhet af sina britludna sepala, samt temligen lâng̣t skaftade smâblad, hvilkas undre sida alttid har en viss benägenhet att blifva hvitluden. Stammen är vanligen försedd med borst, glandler eller hâr, om man undantager $R$. thyrsoideus, som förmedlar öfrergângen till föregående afdelning, wen likräl naturenligast synes böra hänföras till denna grupp.

IV. R. thyrsoideus Wim. caule foliifero arcuato angulato sulcato, aculeis fuscis teretibus falcatis instructo, subglabro, foliolis superne glabris, nitidis et planis, infimis duobus foliolis foliorum rami floriferi subsessilibus, extimo brevius petiolato, late cordato, asi paniculæe cano-villosa, 
aculeis parvis falcatis munita. Flores suavcolentes, styli sape dilute carnei?

R. thyrsoideus Wimm. I. c. pag. 431; Arrh. I. c. pag. 28 ; Fr. I. c. pag. 165 ; Hartm. I. c. pag. 158 ; Gren. et Godr. I. c. pag. 347 ; R. fruticosus Whe. et N. ab. Es. I. c. pag. 24 tab. VII; R. candicans Rchb. I. c. pag. 601 .

I Skâne har jag blott vid Stenshufrud funnit detta species och äfven der temligen sparsamt.

Liksom alla de öfriga $i$ denna afdelning bibehâller äfven denna art på alla de ställen, jag sett den, sin ursprungliga form och synes ej variera till den grad, som de föregående arterna. Den sỵnes vara närmast beslägtad â ena sidan med $R$. affinis, â andra med $R$. discolor. Frân $R$. affinis skiljes den lăttast genom sina hvitludna sepala, mera krökta taggar, samt på undre sidan vanligen hvitludna blad och mera sammansatt inflorescens. Med afseende pâ bladens beklädnad förekomma tvenne former, som dock helt och hållet bero af vextställets beskaffenhet.

a) canescens Fr. Herb. Norm. foliis subtus niveotomentosis.

Förekommer pâ torra, för solen utsatta ställen.

$\beta$ ) virescens foliis subtus virescentibus.

Ej sällsynt på fuktiga ocb skuggrika ställen.

$R$. discolor Whe. caule foliifero angulato lineolato, aculeis valde compressis rectis, stramineis munito, pilis strigoso, foliolis superne opacis rugosis pilosisque, infimis duobus foliolis foliorum rami floriferi petiolatis, extimo longius petiolato, basi cordato, axi paniculæ cano-villosa, aculeis maximis valde falcatis munita. 
R. discolor Whe. et N. ab. Es. I. c. pag. 46 tab. XX; Rchb. I. c. pag. 603; Gren. et Godr. I. c. pag 546 ; Hartm. I. c. pag. 158 ; Fr. l. c. pag. 165; R. vulgaris * discolor Arrh. I. c. pag. 32; R. fruticosus Sm. FI. Brit. 2 pag. 542; Babingt. Brit. Bot. pag. 94.

I östra Skâne har jag blott funnit denna art vid Eljaröd.

Från föregâende art, hvilken den nỵss beskrifna stâr nārmast, skiljes den genast genom sin habitus. De stora sammantrỵchta gula taggarne och de pâ öfre sidan mörkt gröna blad förlāna den ett helt egendomligt utseende. De gemensamma bladskaften pâ de sterila stammarne ảro hos denna art af ungefärligen samma lāngd, som sjelfva hladen, då de deremot hos föregâende āro mỵcket kortare, ăfrensom smâbladen hos $R$. discolor äro vida lāngre skaftade. Bladskaften ăro mỵchet tătt bevăpnade med starkt krökta arter.

R. Radula Whe. caule foliifero angulato lineolato, aculeis rectis, pilis aciculisque sæpe glanduliferis munito, foliolis superne glaberrimis lævibus, infimis duobus foliolis foliorum rami floriferi petiolatis, extimo breviter petiolato, orato, basi plerumque attenuato, axi paniculæ canescenti-pilosa, glandulis aculeisque gracillimis rectis armata.

R. Radula Whe. et N. ab. Es. I. c. pag. 100, tab. XXXIX; Reichb. I. c. pag. 606 ; Hartm. I. c. pag. 158; Fr. I. c. pag. 166 ; R. vulgaris * Radula I. c. Arrh. p. 34 . Vid Stenshufvud förekommer denna art ej sparsamt. Jag har redan förut fitrat, att de arter, som höra till 
denna grupp, băttre ăn de öfriga Rubi sỵnas på hvarje lokal bibehâlla de karakterer, som utmärka dem. Äfven denna art gör ej undantag härifrân. Dess vanligen bruna af hår, borst och taggar, străfva stam, dess skaftade mot basen vanligen afsmalnande, på öfra sidan glatta och glănsande småblad, âtskiljer den straxt frân alla nårbeslägtade arter. De gemensamma bladskaften på den serila stammen äro mycket kortare, än sjelfva bladet; men bladskaften på de blombärande gुrenarna äro ofta längre. Tağgarna äro bruna samt mycket svagare än hos föregående art, raka på den bladbärande stammen, men krökta blandade med raka på de blombärande grenarne och bladskaften, samt slutligen raka i vippan.

Sect. III. Rubi caule arcuato-decumbente vel prostrato, foliis caulis foliiferi 5 -nato-digitatis, foliolis duobus infimis sessilibus, tamquam appendiculatis, intermediis breviter petiolatis, foliis caulis floriferi 3-natis, foliis infimis sessilibus et basi latissimis, omnibus superne glabriusculis, subtus e viridi cano-tomentosis, panicula magis minusve composita subcorymbosa, pedunculis tamquam farinaceis, sæpe nigro-glandulosis, sepalis albo-tomentosis, fructibus maturis adpressis, petalis ovatis brevissime unguiculatis. Styli sape dilute carnei!

Voro arterua i föregående grupp sinsemellan väl begränsade och constanta, så äro de deremot i denna sâ förānderliga och i bvarandra öfvergående, att knappt nîgon gräns sỵnes dem emellan. I östra Skåne, sărdeles kring Stenshufvud, förelomma dessa arter i största mängd och derstädes finnas så många öfvergångar mellan arter, 
som förut af många varit ansedda văl bestămda, att ingen, som derstädes haft tillfälle att noggrannt undersöka dem, skall kunna neka, att $R$. corylifolius, Wahlbergii, nemorosus och pruinosus, böra rätteligen inskiränkas till tvâ arter, nemligen R. corylifolius och nemorosus. Flera författare förena äfien dessa begge arter t. ex. Weilıe och Reichenbach m. fl. Sähert är, att äfven mellan dem finnas många öfvergângar, ehuru det ännu ej lâter afğ̈ra siğ, om de böra betraktas som en art, dá de ỉ andra sidan visa flera olikheter.

R. corylifolius Sm. caule foliifero basi tereti, apice rotundato-angulato, arcuato glabro vel pilis sparsis instructo, aculeis rectiusculis, panicula densa, composita subcorymbosa.

R. corylifolius Sm. FI. Britt. II, pag. 542; Babingt. Britt. Bot. pag. $9 \ddot{z} ;$ Arrh. I. c. pag. 16 ; Hartm. I. c. pag. 159 ; Fr. I. c. p. 168.

Var. intermedius Wahlb. aculeis caulis ramorum floriferorum validioribus magis falcatis, petalis rotundatoovatis.

R. corylifolius var. intermedius Wahlb. Fl. Gothob. pag. 5\%. R. Wahlbergii Arrh. I. c. pag. 43; Hartm. I. c. pag. 159 ; Fr. I. c. pag. 167; Gren. et Grodr. 1. c. pag. 539 ; R. dumetorum e vulgaris Whe. et N. ab. Es. I. c. pag. 101, tab. XLV. A, f. 1 (sec. Gren. et Godr.).

Med otaliga öfrergångar sinsemellan förekomma dessa hegge former i största măngd i hela östra .Skâne. R. Wahlbergï, som efter Arrhenii förträfliga afhandling om de Svenska Rubi af vâra författare allmänt blifvit ansedd som en egen art, torde med mera släl böra anses 
för en varietet af $R$. corylifolius, Såsom grund för dess arträttighet anföres, att den har blomgrenarne bevāpnade med starka krökta taggar, kronbladen bredt ăggrunda, samt frulten svartblå. Hvad för det första taggarna beträffar, sâ äro de äfven pâ de exemplar af $R$. corylifolius, som Arrhenius sjelf tagit, krökta pâ blomgrenarna och $\mathrm{i}$ vippan. Den i östra Skâne allmännast förekommande formen af $R$. Wahlbergii har taggarne på blomgrenarne svagare och mindre krökta, än på exemplar af $R$. corylifolius, tagna af Arrhenius sjelf, ehuru ingen, som sett denna form, lār kunna neka att det är den i Arrh. Mon. beskrifna $R$. Wahlbergii. Kronbladen äro hos hela denna afdelning bredt äggrunda med kort klo och beskrifvas sâlunda af de flesta författare. På bärens färg har jag ej kunnat finna den ringaste olikhet; när de äro i ett mera omoget tillstând, stöta de i rödt, men fullt mogna, blifva de mörkare. Jag för min del är i sanning öfvertygad, att de blott äro de yttersta formerna i den serie af förändringar, som samma art genomgår. I denna förmodan styrkes jag äfven deraf, att ytterst fả författare hafva begge dessa former upptagna som egna arter, utan blott en af dem, så att under den ena, äfven den andra formen innefattas. Så t. ex. är det troligt att $R$. Wahlbergii Gren. et Godr. äfven innefattar $R$. corylifolius och $R$. corylifolius $\mathrm{Sm}$. et Babingt. på samma sätt $R$. Wahlbergï.

Anm. Jag har redan förut omtalat, att öfvergângar mellan $R$. corylifolius och nemorosus ofta finnas. Till bevis härför anföres här en form, som synes hafva lånat karakterer af bâda arterna; den tyckes dock böra hänföras till $R$. corylifolius. 
R. corylifolius var. caule omnino tereti, prostrato, cæsio-pruinoso, aculeis caulis foliiferi rectis, floriferi validis falcatis, panicula composita, densa et subcorymbosa.

R. nemorosus Hayn. caule foliifero tereti, apice plerumque rotundato-angulato, prostrato, cæsio-pruinoso, aculeis rectiusculis vel falcatis munito, panicula subsimplici corymbosa.

R. nemorosus Hayne Arzneygewächse tom. III, tab. X; Fr. I. c. p. 168 ; Arrh. I. c. p. 45 ; IIartm. I. c. p. 159 ; Gren. et Godr. I. c. pag. 539; Wimmer Fl. von Schles. pag. 132; R. dumetorum Whe. et N. ab. Es. I. c. pag. 98, tab. XLV (pro parte).

Allmăn i östra Skåne. De vanligaste formerna derstädes äro a. och b. Arrh. Monogr.

Emellan $R$. pruinosus och nemorosus rảder till en del samma förhâllande, som mellan $R$. corylifolius och Wahlbergii. Exemplar af begge formerna i Herb. Norm., tagna af Arrhenius sjelf, visa ej den ringaste olikhet sinsemellan. Den sterila stammens blad hos R. nemórosus beskrifvas bâde af Weihe och Wimmer sâsom stundom varande septenata, och kronbladen sâsom varande rotundato-ovata, sâ att det är temligen troligt att $R$. pruinosus af dem föres till $R$. nemorosus eller dumetorum. Detsamma, som yttrats om taggarna och bărens fărg hos föregående, găller äfven om dessa begge former.

Polygonum viviparum $L$. caule simplici erecto monostachyo, spica densa cylindrica, foliis lanceolatis, basi attenuatis, revolutis, petiolis apteris. 
Denna art, som förut ej varit funnen i Skåne, ār af Stud. G. D. E. Roth tagen i skogen vid Bjersgård i nordvestra Skåne.

Juncus articulatus var. congestus foliis nodulosis, culmum erectum subæquantibus, floribus in anthelam densifloram congestis, glumis æquilongis, exterioribus acutis, interioribus obtusiusculis capsula brevioribus.

Denna afart förekommer sparsamt på södra stranden af Ringsjön, mellan Finlult och Ousbyholm, på sandiga, fuktiga ställen. Stud. C. D. E. Roll. 



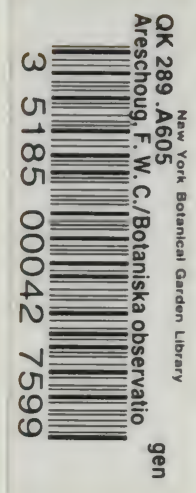


